Editorial

\title{
Coastal seas in a changing world: Anthropogenic impact and environmental responses
}

In recent decades, human-driven environmental change caused by the modification of river discharges, the exploitation of marine resources, the burning of fossil fuels, and various shoreline developments and engineering activities, has accelerated; and evidence of this is seen around the world. Linking continents with open oceans, coastal seas trap most land-based discharge and consequently face varying degrees of anthropogenic change.

This special issue contains original research articles that address the documentation and interpretation of the scope of anthropogenic change to coastal and continental shelf environments. Covered topics include but are not limited to: the underlying physical and biogeochemical processes that drive observed environmental changes; environmental responses; and mitigation strategies. Environments of interest include estuaries, coastal wetlands, and continental shelves, as well as their neighboring environments. Fundamental research papers covering such areas as physical transport processes including boundary-layer processes and sediments, chemical and geochemical processes, and ecological responses to environmental change are included in this special issue.

\section{Physical transport processes}

Two of the largest rivers in the world - the Huanghe (Yellow River) and the Changjiang (Yangtze River) - empty into the Bohai and East China Seas (ECS). Zeng et al. (2015) simulated and analyzed the coastal circulation and transport of sediments from the Huanghe and Changjiang Rivers in the Bohai, Yellow, and East China Seas from 1958 to 2005 using the Coupled Ocean-Atmosphere-Wave-Sediment Transport modeling system. They found that the system generally reproduced the observed hydrodynamic environment and sediment transport pattern. The formation of muddy patches close to river mouths depended largely on their proximity to the sediment source, while the formation of muddy patches in regions farther from the river mouths were caused by weak local bottom strand associated circulation patterns. Strong seasonal variations were found in the transport of river-derived sediment, with stronger offshore sediment transport in the winter than in the summer. Further, water and sediments are now regulated for the Huanghe River (Wu et al., 2015). The result is that the medium grain size of sediments discharge to the sea has significantly increased. Consequently, more sediment accumulated in the nearshore area, which effectively extended the subaerial delta and steepened the subaqueous slope off the present river mouth.
Human activities are affecting the transport of riverine sediment and the sea-level, modifying the evolution of deltas around the world. In the last century, the Brazos River delta in Brazil, for example, has been modified by changes made to agricultural land, jetty construction, mouth diversion, and the construction of reservoirs (Carlin and Dellapenna, 2015). Shifts in erosion and deposition areas are apparent above the water, but less detectable in the subaqueous delta. In the Mississippi Sound, U.S.A., the construction of navigational channels and other activities have resulted in erosion in the Grand Bay Estuary, leading to the submergence of a protective barrier island (Passeri et al., 2015).

Modeling studies reveal that these changes have changed tide heights and velocities in the Grand Bay. Further human activities in the Whidbey Basin of the Puget Sound have caused the loss of intertidal flats (Yang and Wang, 2015). Models reveal that these losses change patterns of salinity intrusion and water circulation, potentially increasing the risk of storm surges and coastal flooding. Flood protection works, dredging for navigation purposes, and land reclamation have affected the morphology of the Scheldt Estuary and the Wadden Sea basins in the Netherlands and the Yangtze Estuary in China (Wang et al., 2015b). In the Yangtze River, upstream dams in particular, have had large effects. The aforementioned human activities interact with the accelerating rise in sea-level that is caused by climate change, potentially driving basins past critical thresholds of irreversible change (Wang et al., 2015b).

\section{Chemical and geochemical processes}

As well as transporting sediments, rivers deliver a large amount of nutrients to the coastal oceans. Wei et al. (2015) utilized historical data to determine the long-term variations of nutrients in the southern Yellow Sea. The concentration of dissolved inorganic nitrogen in the southern Yellow Sea has increased continuously since the 1980s but the $\mathrm{N} / \mathrm{P}, \mathrm{Si} / \mathrm{N}$ and $\mathrm{Si} / \mathrm{P}$ ratios varied rapidly following the mid-1990s. These variations are related to variations in the riverine flux and atmospheric deposition. Wei et al. noted that the transport of nutrients from the Kuroshio Subsurface Water to the continental shelf (Chen, 1996), in combination with the eutrophication in the coastal zones, may also influence the nutrient levels in the southern Yellow Sea.

Dai et al. (2015) also discussed nutrients. They utilized linear programming and 3D biogeochemical-hydrodynamic models to estimate the total maximum allocated loads (TMAL) for nitrogen pollutants around the Bohai Sea. The TMAL of nitrogen pollutants was 
$1.49 \times 10^{5} \mathrm{t} /$ year in 2010 . They found the highest TMAL in summer, and the lowest in winter. TMAL was also higher in the Bohai Strait and the central Bohai Sea than in the inner area of the Liaodong Bay, Bohai Bay, and Laizhou Bay.

The work of four articles in this special issue is related to the coastal seas as a sink or source of atmospheric $\mathrm{CO}_{2}$ and coastal water acidification (Huang et al., 2015; Lui et al., 2015; Omstedt et al., 2015; Qu et al., 2015). Huang et al. (2015) observed upwelling-favorable winds and an offshore Mississippi and Atchafalaya River plume trajectory in the summer of 2007 and 2009, which contrasted with the prevailing conditions from 2002 to 2010 (upwelling-unfavorable winds and an alongshore river plume trajectory). Overall, surface waters on the continental shelf in the region of interest in July 2009 were a weak source of $\mathrm{CO}_{2}$ to the atmosphere, but in August 2007, they were a weak $\mathrm{CO}_{2}$ sink.

Qu et al. (2015) studied the surface partial pressure of $\mathrm{CO}_{2}\left(\mathrm{pCO}_{2}\right)$ and related parameters $(\mathrm{pH}$, total alkalinity, dissolved oxygen, chlorophyll a) in the southern Yellow Sea and the ECS, based on two surveys that were carried out in June and August of 2013. The western part of the southern Yellow Sea was $\mathrm{CO}_{2}$-undersaturated in both June and August and the center of the southern Yellow Sea also functioned as a $\mathrm{CO}_{2}$ sink. Further, the Yangtze River estuary changed from being an obvious $\mathrm{CO}_{2}$ sink in June, to being a very weak $\mathrm{CO}_{2}$ source in August. The inner shelf of the ECS saw much changes in the air-sea $\mathrm{CO}_{2}$ flux from June to August. Overall, the study area acted as $\mathrm{CO}_{2}$ sinks in the summer and absorbed atmospheric $\mathrm{CO}_{2}$ with a mean air-sea flux of $-2.68 \mathrm{mmol} \mathrm{m}^{-2} \mathrm{~d}^{-1}$.

Lui et al. (2015) presented observed acidification rates at the shelf break of ECS, and in the Okinawa Trough between 1982 and 2007. They utilized apparent oxygen utilization (AOU) data to quantify changes in $\mathrm{pH}$ that were caused by physical changes and changes in biological activities. Their results demonstrated that, like the intrusion of atmospheric $\mathrm{CO}_{2}$, the increase in AOU concentration contributed to the drop in $\mathrm{pH}$ of the Kuroshio Intermediate Water in the ECS. When the effects of changing AOU and potential temperature were eliminated, the acidification rate in the basin of the ECS was consistent with the rate of change that was induced by the increase in anthropogenic $\mathrm{CO}_{2}$ concentration, while its value at the shelf break was $69 \%$ higher than the rate based on an assumption of air-sea $\mathrm{CO}_{2}$ equilibrium. This fact may suggest that the seawater in the South China Sea (SCS), coastal ECS water, or a combination of them, had a higher acidification rate than the water in the Okinawa Trough during the period of interest, because the seawater on the ECS shelf contained proportionally more SCS seawater and coastal water.

In addition to the influence of atmospheric $\mathrm{CO}_{2}$, the deposition of acidifying and eutrophying species from atmosphere also contributes significantly to the ocean acidification. Omstedt et al. (2015) studied the effects of historical atmospheric depositions of sulphate, nitrate, and ammonium originated from land and shipping on the acid-base balance of the Baltic Sea. Their process-based model was applied to the period 1750-2014. The results obtained demonstrate that the acidification of the Baltic Sea by the atmospheric deposition of acids peaked around 1980 .

As coastal eutrophication has become a global problem, early detection of suboxic or anoxic waters is desirable. Ding et al. (2015) developed an optimized all-solid-state $\mathrm{Ag} / \mathrm{Ag}_{2} \mathrm{~S}$ electrode for the identification of a product of eutrophication, $\left[\mathrm{S}^{2-}\right]$, in seawater. Marguš et al. (2015), ${ }^{1}$ successfully applied atomic force microscopy to investigate the anoxic stress conditions in a water column of a highly eutrophic and sulfidic marine environment in the eastern Adriatic. The results indicated that diverse types of organic matter were formed in different seasons and under various physicochemical conditions.

\footnotetext{
${ }^{1}$ Because of technical problems Marguš et al. (2015) and Zikhali et al. (2015) already appeared in regular issues.
}

Hu et al. (2015) performed comprehensive research on the source of $\mathrm{Pb}$ in surface sediments of the Liaodong Bay in the Bohai Sea. The total concentrations of $\mathrm{Pb}$ and the ratios of its stable isotopes $(207 \mathrm{~Pb} / 206 \mathrm{~Pb}$ and $208 \mathrm{~Pb} / 206 \mathrm{~Pb})$ were determined. The results revealed that most $\mathrm{Pb}$ in the southern Liaodong Bay was naturally derived. However, its concentration was significantly affected by anthropogenic sources in the northern and southwestern parts of the bay, including coal combustion, vehicle emissions, and $\mathrm{Pb}$ ores.

Wang et al. (2015a) examined the spatial distribution of dissolved cadmium along with other hydrochemical parameters in a large subtropical river estuary system (the Jiulong River-Estuary, China) between 2008 and 2010. The results showed that dissolved $\mathrm{Cd}$ in the watershed had sporadically high concentrations $\left(>0.6 \mathrm{nmol} \mathrm{L}^{-1}\right)$. The significantly positive correlation of dissolved $\mathrm{Cd}$ with phosphate in the watershed indicated that dissolved Cd levels had elevated along with $\mathrm{P}$ due to the increasing agricultural discharges and/or sewage effluents.

\section{Ecological responses to environment changes}

Changes in physical and biogeochemical conditions affect ecosystems. Chen et al. (2015a) estimated the annual and interannual carbon fixation induced by typhoons in the South China Sea (SCS) and the Western North Pacific Subtropical Ocean (WNPSO). The annual carbon fixation due to typhoons in the whole SCS was estimated to be equivalent to $5-10 \%$ of the new primary production of the SCS. This suggests that typhoons have contributed to the biological carbon fixation in the SCS. In terms of the WNPSO, the annual mean carbon fixation due to typhoons was small. The main reason is that the cold nutrient-rich water is more difficult to be transported to the upper layer to support the growth of phytoplankton due to the deep mixed layer and nutricline in the WNPSO in comparison with the SCS.

Zikhali et al. (2015) (see footnote 2) successfully modeled the wind-induced re-suspension of sediments in Lake St. Lucia, the largest estuarine lake in Africa, underlining the importance of physical processes to primary production as well as sediment budgets. Carrasco and Perissinotto (2015) investigated changes in zooplankton dynamics in St. Lucia lake as it changed from dry to wet. Their study reported on the transition of the St Lucia zooplankton community from a dry hypersaline state to a new wet phase. The recorded increase in the richness of zooplankton species revealed that the system had undergone a transition to a wet state, and that the present zooplankton community structure reflected what was recorded in the past. Only a full restoration of natural estuarine functioning is likely to increase diversity further.

Zheng et al. (2015) studied the grazing by microzooplankton on phytoplankton and primary production in the ECS, which is a very productive area in the western Pacific Ocean. They did not find a significant difference in phytoplankton growth rate or microzooplankton grazing rate, between river-affected coastal water and Kuroshio-influenced offshore water. Rather, they found that phytoplankton growth rates were positively correlated with temperature and that microzooplankton grazing balanced the primary production is summer while it was low in winter.

Chen et al. (2015b) investigated the trophic structure, ecosystem properties, and keystone species in Daya Bay - which is one of the important bays along the South China Sea - using a food-web model. They found that the mean trophic transfer efficiency of the entire ecosystem was $10.9 \%$ and that of the trophic level II was $5.1 \%$. Phytoplankton, zooplankton, and micro-zoobenthos were important keystone groups. The ecosystem seemed to be more stressed than other coastal ecosystems. The authors suggested the importance of a holistic approach, with a food-web model, to minimizing anthropogenic impacts. 
Various anthropogenic impacts, including some of those mentioned above, have induced responses from the biota. Sureda et al. (2015) studied the physiological state of the Posidonia oceanica, the main seagrass in Porto Cristo in Spain. They found that the structure and oxidative biomarkers (such as catalase, superoxide dismutase, glutathione peroxidase) indicated that $P$. oceanica in the bay was generally in good condition, but that humans have affected the area closest to the harbor and the beach.

Mondol et al. (2015) compared the physiological conditions of samples of an oyster species, Crassostrea gigas - which is an economically valuable and widely cultured marine bivalve - collected from a contaminated location following an oil spill, along with samples collected from a non-contaminated location. Based on the evidence, the samples from the contaminated location exhibited better biological performance than those from the non-contaminated location. The authors inferred that the Pacific oysters had successfully recovered from the detrimental impact of petroleum contamination within two years.

Leitão (2015) investigated the relationships between environmental factors and Atlantic horse mackerel (Trachurus trachuus) catch rates along the coast of Portugal using time-series models. He identified different physical processes that controlled the catch rates in three regions along the coast. He also suggested the development of regional management measures for the long-term.

\section{Conclusions}

As a set the studies in this special issue present specific examples of how anthropogenic activities of diverse types are having significant, interactive, impacts on coastal sea environments. Moreover, the changes in levels of sediment, physical transport processes, and biogeochemistry are triggering biotic responses and feedbacks. More special issues of its kind are sure to appear in the future to elucidate and expand these issues in more detail.

\section{References}

Carlin, J.A., Dellapenna, T.M., 2015. The evolution of a subaqueous delta in the Anthropocene: a stratigraphic investigation of the Brazos River delta, TX USA. Cont. Shelf Res. 111 (B), 139-149.

Carrasco, N.K., Perissinotto, R., 2015. Zooplankton community structure during a transition from dry to wet state in a shallow, subtropical estuarine lake. Cont. Shelf Res. 111 (B), 294-303.

Chen, C.T.A., 1996. The Kuroshio intermediate water is the major source of nutrients on the East China Sea continental shelf. Oceanol. Acta 19, 523-527.

Chen, X.Y., Pan, D., Bai, Y., He, X.Q., Chen, C.T.A., Kang, Y., Tao, B., 2015a. Estimation of typhoon-enhanced primary production in the south China Sea: a comparison with the western north pacific. Cont. Shelf Res. 111 (B), 286-293.

Chen, Z., Xu, S., Qiu, Y., 2015b. Using a food-web model to assess the trophic structure and energy flows in Daya Bay, China. Cont. Shelf Res. 111 (B), 316-326.

Dai, A., Li, K., Ding, D., Li, Y., Liang, S., Li, Y., Su, Y., Wang, X., 2015. Total maximum allocated load calculation of nitrogen pollutants by linking a 3D biogeochemical-hydrodynamic model with a programming model in Bohai Sea. Cont. Shelf Res. 111 (B), 197-210.

Ding, Q., Pan, Y.-w, Huang, Y.-f, Chen, C.-T.A., Ye, Y., 2015. The optimization of $\mathrm{Ag} / \mathrm{Ag}_{2} \mathrm{~S}$ electrode using carrier electroplating of nano silver particles and its preliminary application to offshore Kueishan Tao, Taiwan. Cont. Shelf Res. 111 (B), 262-267.

Hu, N., Huang, P., Zhang, H., Zhu, A., He, L., Zhang, J., Liu, J., Shi, X., Ma, D., 2015. Tracing the $\mathrm{Pb}$ origin using stable $\mathrm{Pb}$ isotope ratios in sediments of Liaodong Bay, China. Cont. Shelf Res. 111 (B), 268-278.

Huang, W.J., Cai, W.J., Wang, Y., Hu, X., Chen, B., Lohrenz, S.E., Chakraborty, S., He, R. Brandes, J., Hopkinson, C.S., 2015. The response of inorganic carbon distributions and dynamics to upwelling-favorable winds on the northern gulf of Mexico during summer. Cont. Shelf Res. 111 (B), 211-222.

Leitão, F., 2015. Time series analyses reveal environmental and fisheries controls on
Atlantic horse mackerel (Trachurus trachurus) catch rates. Cont. Shelf Res. 111 (B), 342-352.

Lui, H.-K., Chen, C.-T.A., Lee, J., Wang, S.-L., Gong, G.-C., Bai, Y., He, X., 2015. Acidifying intermediate water accelerates the acidification of seawater on shelves: an example of the East China Sea. Cont. Shelf Res. 111 (B), 223-233.

Marguš, M., Ciglenečki, I., Batina, N., Morales-Reyes, I., Bura-Nakić, E., 2015. The anoxic stress conditions explored at the nanoscale by Atomic Force Microscopy in highly eutrophic and sulfidic marine lake. Cont. Shelf Res. 109, 24-34.

Mondol, M.R., Keshavmurthy, S., Lee, H.-J., Hong, H.-K., Park, H.-S., Park, S.-R., Kang, C.-K., Choi, K.-S., 2015. Recovery of wild Pacific oyster, Crassostrea gigas in terms of reproduction and gametogenesis two-years after the Hebei Spirit Oil Spill Accident off the West Coast of Korea. Cont. Shelf Res. 111 (B), 333-341.

Omstedt, A., Edman, M., Claremar, B., Rutgersson, A., 2015. Modelling the contributions to marine acidification from deposited $\mathrm{SO}_{x}, \mathrm{NO}_{x}$, and $\mathrm{NH}_{x}$ in the Baltic Sea: past and present situations. Cont. Shelf Res. 111 (B), 234-249.

Passeri, D.L., Hagen, S.C., Medeiros, S.C., Bilskie, M.V., 2015. Impacts of historic morphology and sea level rise on tidal hydrodynamics in a microtidal estuary (Grand Bay, Mississippi). Cont. Shelf Res. 111 (B), 150-158.

Qu, B., Song, J., Yuan, H., Li, X., Li, N., Duan, L., Chen, X., Lu, X., 2015. Summer carbonate chemistry dynamics in the Southern Yellow Sea and the East China Sea: regional variations and controls. Cont. Shelf Res. 111 (B), 250-261.

Sureda, A., Box, A., Tejada, S., 2015. Assessment and physiological state of the Posidonia oceanica meadows in Porto Cristo (Manacor, Spain). Cont. Shelf Res. 111 (B), 327-332.

Wang, D.L., Yang, X.Q., Zhai, W.D., Li, Y., Hong, H.S., 2015a. Spatial distribution of dissolved cadmium in the Jiulong River-Estuary System: Relevance of anthropogenic perturbation. Cont. Shelf Res. 111 (B), 279-285.

Wang, Z.B., Van Maren, D.S., Ding, P.X., Yang, S.L., Van Prooijen, B.C., De Vet, P.L.M., Winterwerp, J.C., De Vriend, H.J., Stive, M.J.F., He, Q., 2015b. Human impacts on morphodynamic thresholds in estuarine systems. Cont. Shelf Res. 111 (B), 174-183.

Wei, Q., Yao, Q., Wang, B., Wang, H., Yu, Z., 2015. Long-term variation of nutrients in the southern Yellow Sea. Cont. Shelf Res. 111 (B), 184-196.

Wu, X., Bi, N.S., Yuan, P., Li, S., Wang, H.J., 2015. Sediment dispersal and accumulation off the present Huanghe (Yellow River) subdelta as impacted by the Water-sediment Regulation Scheme. Cont. Shelf Res. 111 (B), 126-138.

Yang, Z., Wang, T., 2015. Responses of estuarine circulation and salinity to the loss of intertidal flats - a modeling study. Cont. Shelf Res. 111 (B), 159-173.

Zeng, X., He, R., Xue, Z., Wang, H., Wang, Y., Yao, Z., Guan, W., Warrillow, J., 2015. River-derived sediment suspension and transport in the Bohai, Yellow, and East China Seas: a preliminary modeling study. Cont. Shelf Res. 111 (B), 112-125.

Zheng, L., Chen, B., Liu, X., Huang, B., Liu, H., Song, S., 2015. Seasonal variations in the effect of microzooplankton grazing on phytoplankton in the East China Sea. Cont. Shelf Res. 111 (B), 304-315.

Zikhali, V., Tirok, K., Stretch, D., 2015. Sediment resuspension in a shallow lake with muddy substrates: St Lucia, South Africa. Cont. Shelf Res. 108, 112-120.

Managing Guest Editor
Chen-Tung Arthur Chen
Department of Oceanography, National Sun Yat-sen University,
Kaohsiung 80424, Taiwan
E-mail address: ctchen@mail.nsysu.edu.tw
Guest Editor
Xuelu Gao

Key Laboratory of Coastal Zone Environmental Processes and Ecological Remediation, Yantai Institute of Coastal Zone Research, Chinese Academy of Sciences, Yantai, Shandong 264003, China E-mail address: xlgao@yic.ac.cnc.ac.cn

\author{
Guest Editor \\ Joji Ishizaka \\ Institute for Space-Earth Environmental Research (ISEE), Nagoya \\ University, Nagoya, Aichi 464-8601, Japan \\ E-mail address: jishizaka@nagoya-u.jp
}

Guest Editor
Louis Lebel
Unit for Social and Environmental Research, Chiang Mai University,
Chiang Mai 50200, Thailand
E-mail address: llebel@loxinfo.co.th

Guest Editor

Louis Lebel

E-mail address: llebel@loxinfo.co.th 